\title{
ESTANDARIZACIÓN DE LA EXTRACCIÓN DE ADN GENÓMICO EN Tabebuia rosea (Bertol.) DC. Y Cordia alliodora (Ruiz \& Pav.) Okén
}

\section{STANDARDIZING GENOMIC DNA EXTRACTION IN Tabebuia rosea (Bertol.) DC. AND Cordia alliodora (Ruiz \& Pav.) Okén}

\author{
Paola A. López-Mora' ${ }^{1}$ Ana M. López-Gutiérrez¹, Marta L. Marulanda-Ángel ${ }^{1}$
}

Recibido para publicación: Septiembre 14 de 2011 - Aceptado para publicación: Diciembre 22 de 2011

\begin{abstract}
RESUMEN
El potencial comercial y el papel que desempeñan en la protección del medio ambiente, Cordia alliodora y Tabebuia rosea las torna relevantes en el Plan Nacional de Reforestación, el cual es ejecutado por la Corporación Nacional de Investigación y Fomento Forestal (CONIF) y el Ministerio de Agricultura y Desarrollo Rural (MADR) de Colombia. El avance de las técnicas de biología molecular, permite la disponibilidad de nuevas herramientas en el mejoramiento genético vegetal, fomentando la fijación de genes involucrados en la expresión de caracteres fenotípicos deseables de interés comercial y productivo. El objetivo fue estandarizar un método de extracción de ADN genómico específico a partir de tejido foliar fresco y seco, al igual que de plántulas. Se encontraron diferencias significativas entre las dos especies. En C. alliodora el tipo y estado del tejido no fue un factor limitante para la extracción, la cual dependió solamente del método empleado. Por el contrario, T. rosea presentó limitaciones en la extracción y amplificación del ADN obtenido a partir de tejido seco, lo cual se atribuyó a la concentración significativa de polisacáridos, polifenoles y otros metabolitos secundarios, también reportados en otras investigaciones para esta especie. Se cuantificó el ADN extraído y se evaluó su calidad mediante la amplificación del ADN utilizando microsatélites. Los datos se sometieron a Análisis de Componentes Principales (ACP) y Análisis Factorial Múltiple (AFM). Con base en los resultados, se estandarizó un protocolo de extracción de ADN para cada especie y se definió el tejido foliar óptimo para dicho proceso.
\end{abstract}

Palabras clave: ADN, forestales, guayacán, nogal, biotecnología.

\begin{abstract}
Because of their great commercial potential and its role on environmental protection, Cordia alliodora and Tabebuia rosea are among species prioritized by Colombia's National Reforestation Plan, which is executed by

`Universidad Tecnológica de Pereira. Facultad de Ciencias Ambientales. Laboratorio de Biotecnología Vegetal. Vía La Julita, Pereira-Risaralda (Colombia).Telefax: (6)-3215995, Email: ubioteve@utp.edu.co
\end{abstract}


the National Corporation for Forestry Research and Development (CONIF) and the Ministry of Agriculture and Rural Development (MADR). Thanks to the advancement of molecular biology techniques, new tools, that are quite useful in plant breeding, are now available, promoting the fixation of genes involved in the expression of desirable phenotypic traits of commercial and productive interest. This study was aimed to standardize a specific genomic DNA extraction method from fresh and dry leaf tissue as well as from seedlings. Significant differences were observed between both species. In C. alliodora, tissue, type and condition was not a limiting factor for extraction and it only depended on the method used. On the other hand, T. rosea has limitations in DNA extraction and amplification from dry tissue, which was attributed to the high concentration of polysaccharides, polyphenols and other secondary metabolites, also reported in other studies for this species. The extracted DNA was quantified and its quality evaluated by DNA amplification using microsatellites. Data were analyzed by both Principal Component Analysis (PCA) and Multiple Factor Analysis (MFA). Based on the results obtained, a DNA extraction protocol was standardized for each of these species and the optimum leaf tissue for that process was defined.

Key words: DNA, Forest, guayacan, nogal, biotechnology.

\section{INTRODUCCIÓN}

Tabebuia rosea es una especie ornamental, maderable de la familia Bignoniaceae y de tamaño mediano, alcanza de 20 a 25 m de altura. Su tronco es ligeramente acanalado, con pocas ramas gruesas horizontales y ramificación simpódica, con copa estratificada y hojas decusadas distribuidas en panículas cortas (Vit 2004). En Colombia, se conoce con los nombres de guayacán, guayacán rosado, guayacán lila, flor morado, ocobo, guayacán morado, roble, garza y roso. Es nativa en México, América Central y el norte de Sur América (Brasil, Colombia, Ecuador, Perú, Venezuela). Las semillas se dispersan por el viento durante la estación seca (marzo-abril) y germinan durante la primera temporada de Iluvias (mayo-junio) (Kitajima 2002). Se desarrolla naturalmente en las zonas cálidas de las Antillas mayores y menores, y desde allí se ha difundido a toda Centroamérica, crece en una variedad de hábitats, con tendencia a dominar en bosque húmedo bajo, bosque de galería y áreas con inundaciones estacionales. Esta especie prefiere suelos de textura arenosa a franca, tolera suelos ácidos y ocupa un rango actitudinal amplio, el cual oscila entre 0 a 1300 m s n m y su precipitación anual entre 1200 y 2500 mm (OFI-CATIE 2003).

Por su parte, Cordia alliodora, pertenece a la familia Boraginaceae y es un árbol que crece hasta $45 \mathrm{~m}$ de altura y alcanza $90 \mathrm{~cm}$ de diámetro. Su tallo es cilíndrico, corteza externa gris o pardo e interna de color amarillo claro. En Colombia se conoce como nogal o nogal cafetero, pardillo, móncoro, y laurel. Es una especie nativa de América tropical y en la vertiente Atlántica de América Central, crece desde el nivel del mar hasta $800 \mathrm{~m}$ de altitud y hasta $1200 \mathrm{~m}$ en la vertiente del Pacífico (Boshier and Mesén 1989). El nogal alcanza su máximo desarrollo en el bosque húmedo tropical y muy húmedo tropical con precipitaciones mayores de $2000 \mathrm{~mm}$ anuales, aunque puede crecer en zonas secas con alrededor de 1000 mm anuales (Borge 2008).

Colombia posee, evidentemente, un enorme potencial en términos de especies vegetales; el total de especies vasculares silvestres se 
calcula entre 40000 y 50000 (lo cual coloca al país en el segundo a nivel mundial después del Brasil en cuanto a riqueza florística), es por esto que en los últimos años, el Plan Nacional de Desarrollo Forestal ha estimulado la plantación de especies forestales nativas y foráneas de alto valor comercial, con rápida y mediana producción y fácil aplicación en sistemas de producción agroforestales. Dentro de estas especies nativas de interés económico y ecológico, se encuentran el nogal cafetero y el guayacán rosado, los cuales cuentan con gran aceptación y preferencia dentro de las especies forestales comerciales, gracias a que poseen maderas semiduras y livianas, con buenas características de trabajabilidad y otros factores ecológicos que las convierten en especies con un alto potencial de aprovechamiento $y$ conservación (CONIF 2002).

En los últimos años, la aplicación de la biotecnología en la investigación agrícola, ha progresado rápidamente, lo que ha permitido desarrollar múltiples técnicas moleculares de gran utilidad en el mejoramiento vegetal, facilitando el análisis genético de caracteres de interés agronómico y la selección de individuos con características ventajosas (Zamudio y Guerra 2002), ya que se pueden identificar genes que determinen características económicamente importantes, como la tasa de crecimiento, la adaptabilidad, la forma del tronco y la calidad de la madera (densidad y cantidad de lignina), entre otras, una vez conocidos esos genes, se pueden seleccionar los alelos deseados, sin necesidad de esperar años hasta que el árbol sea adulto, de igual forma se puede promover la pérdida de los genes que gobiernan otras características menos deseadas a nivel forestal (Mesén 1994).
Sin embargo, existen algunos factores limitantes de orden técnico y/o económico, entre los cuales se encuentran la disponibilidad de marcadores moleculares que permitan mejorar la cobertura del genoma en cuestión, y procesos sistematizados para la obtención de ADN o reacciones de amplificación a gran escala, ya que la aplicación de esta herramienta de gran alcance en algunas especies de plantas, ha sido limitada por la falta de eficaces técnicas de extracción de los ácidos nucleicos (Sghaier et al. 2005 citado por Matasyoh et al. 2008). Aunque la extracción de ADN en plantas se ha descrito por numerosos autores, cada autor describe un método diferente para superar los problemas para el aislamiento de ADN genómico. Algunas plantas leñosas tienen ciertos metabolitos como compuestos polifenólicos, polisacáridos, taninos y ARN que interfieren con el aislamiento de ADN y la reacción en cadena de la polimerasa (PCR) (Rout et al. 2002).

No obstante, la publicación masiva de trabajos a nivel de extracción de ADN en plantas se viene realizando hasta hace pocos años (Dellaporta et al. 1983, Doyle and Dolyle 1990; Porebski et al. 1997; Zhang and McStewart 2000; Sharma et al. 2002; Li et al. 2002; KebLlanes et al. 2002; Michiels et al. 2003; Alaey et al. 2005; Narayanan et al. 2006; Križman et al. 2006; Deshmukh et al. 2007; Matasyoh et al. 2008), donde se mencionan múltiples inconvenientes debido a la co-extracción de polisacáridos de alta viscosidad, y polifenoles, los cuales actúan como inhibidores durante la extracción del ADN; lo que ocasiona también que el $\mathrm{ADN}$ aislado se observe de un color amarillento, pegajoso y viscoso (Deshmukh et al. 2007). 
Por lo tanto, el objetivo de esta investigación fue estandarizar la extracción de ADN genómico para las especies, T. rosea y $C$. alliodora a partir de tejido seco, adulto y plántulas, para la utilización a largo plazo en programas de mejoramiento genético, a través de marcadores moleculares que permitan la construcción de mapas genéticos, incrementando la probabilidad de identificar regiones cromosómicas que determinen rasgos agronómicamente importantes en ambas especies.

\section{MATERIALES Y MÉTODOS}

\section{Tejido vegetal y recolección del material}

Se emplearon tres tipos de tejido foliar: tejido fresco, tejido seco y plántulas:

a) Tejido Fresco: Se recolectaron hojas de árboles adultos sanos ubicados en el campus de la Universidad Tecnológica de Pereira. Se manejó en hielo desde el momento en que se cortaron del árbol hasta llegar al laboratorio, donde se realizó inmediatamente la extracción del ADN.

b) Tejido Seco: Se recolectaron hojas de árboles adultos sanos ubicados en el campus de la Universidad Tecnológica de Pereira, y se almacenó en Gel de Sílice granulado sin cobalto (Carlo Erba), proporción 1:10 (un gramo de tejido vegetal por 10 gramos de gel de sílice) en bolsas plásticas con cierres herméticos, debidamente rotuladas, alrededor de una semana, posteriormente se realizó la extracción de ADN.

c) Plántulas: Se puso a germinar semillas en el vivero de la Universidad Tecnológica de
Pereira, en cubetas de 128 puestos y fueron trasplantadas 45 días después a bolsas de 17 x $24 \mathrm{~cm}$. Se tomó una muestra de las primeras hojas verdaderas, las cuales se conservaron en hielo Ilevándolas al laboratorio. En todos los casos anteriores, se maceró el tejido foliar utilizando nitrógeno líquido y el tejido macerado se almacenó en tubos cónicos FALCON de $15 \mathrm{~mL}$ debidamente rotulados a $-70^{\circ} \mathrm{C}$. Esto se Ilevó a cabo en el Laboratorio de Biotecnología Vegetal en la Universidad Tecnológica de Pereira.

\section{Protocolos de Extracción}

Para la extracción de ADN genómico en nogal cafetero y guayacán rosado, se empleó como control comercial el Kit Plant DNeasy mini Kit de QIAGEN. Y los tres protocolos de extracción evaluados fueron: Dellaporta et al. (1983) basado en el uso de SDS (Dodecil Sulfato de Sodio), Porebski et al. (1997) y Doyle and Doyle (1990) los cuales son métodos basados en el uso de CTAB (Bromuro de Cetil-Trimetil Amonio).

\section{Tratamiento RNasa A}

Para evitar la presencia de cantidades considerables de $A R N$, se realizó un tratamiento con RNasa A. En este caso, en los cuatro protocolos de extracción se adicionó $2 \mu \mathrm{l}$ de RNasa A $(10 \mathrm{mg} / \mathrm{mL})$ y se llevó a $37^{\circ} \mathrm{C}$ por 30 minutos en baño maría.

\section{Evaluación cuantitativa del ADN aislado}

Para evaluar la calidad del ADN, éste se visualizó por electroforesis horizontal en geles de agarosa al $1 \%$ teñidos con bromuro de etidio $(0,5 \mu \mathrm{g} / \mathrm{ml})$. La electroforesis se corrió en una solución tampón de corrido TBE 1X (500mM de Tris-HC1, 60 mM de ácido bórico y 83 mM 
de EDTA) a una corriente de $90 \mathrm{~V}$ durante 60 minutos. Como marcador de peso molecular se utilizó $1 \mathrm{~kb}$ DNA Ladder $(1 \mu \mathrm{g} / \mu \mathrm{l})$ (Bioline). La electroforesis se corrió con una fuente de poder (Pharmacia Biotech). El gel se visualizó bajo la luz de UV en un documentador de geles modelo GelDoc 1000 de BIO-RAD.

El ADN se cuantificó directamente en una solución acuosa, midiendo la absorbancia (A) de luz ultravioleta y comparando con un blanco o línea base (agua estéril). En este caso la cuantificación del ADN obtenido se calculó en un Espectrofotómetro UV-visible (Shimadzu UV-1700) estimando la absorbancia de la muestra a 260nm, sabiendo que 1 unidad de

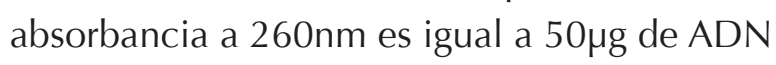
de doble cadena.

\section{Evaluación de pureza del ADN genómico}

La pureza del ADN genómico, se determinó espectrofotométricamente por la medida de absorbancia, ya que la interferencia de contaminantes puede determinarse calculando un «cociente». Teniendo en cuenta, que las proteínas absorben a 280nm, se emplea el cociente A260/A280 para calcular la pureza de los ácidos nucleicos. Para que el ADN obtenido presente suficiente pureza para ser amplificado, debe presentar valores entre 1,7 y 2,0 (Becker et al. 1996).

\section{Evaluación de calidad del ADN genómico}

La calidad se verificó por medio de la amplificación del ADN utilizando microsatélites desarrollados por el Laboratorio de Biotecnología Vegetal de la Universidad Tecnológica de Pereira, los cuales fueron diseñados con el software Designer PCR, versión 1.03 (Research Genetics, Inc $($ )), las secuencias de los microsatélites obtenidos se encuentran en el GenBank. En la especie C. alliodora se utilizaron los iniciadores: CA104 F (5'-ATTGCTTTCTCAGTCCTATTC-3') y CA104 R (5'-ATGGTGAGTATTGGATGATCC-3') (número de accesión GenBank GU011894), y para $T$. rosea se utilizaron los iniciadores: TRB110 F (5'-ACCCAGGAAATGTTCTCG-3') y TRB110 R (5’-AACGGTTGAGGAGCCATC-3') (número de accesión GenBank GU011754). La amplificación se llevó a cabo en un termociclador (MJ Research PTC 100) en un volumen final de $15 \mu \mathrm{l}$ con $0.9 \mu \mathrm{M}$ de cada uno de los iniciadores, $1 \mathrm{U}$ de Taq polimerasa, $200 \mu \mathrm{M}$ de cada uno de los dNTP, 1X de buffer de reacción $(10 \mathrm{mM}$ de Tris $\mathrm{HCl}, 50 \mathrm{mM}$ de $\mathrm{KCl}, 1,5 \mathrm{mM}$ de $\mathrm{MgCl} 2$ ) y 10 ng de ADN (López 2009).

El perfil de amplificación fue de 30 ciclos de $94{ }^{\circ} \mathrm{C}$ por un minuto, temperatura de apareamiento por un minuto, $72^{\circ} \mathrm{C}$ por un minuto, con una extensión final de $72{ }^{\circ} \mathrm{C}$ por 10 minutos. La visualización de los fragmentos se realizó en geles desnaturalizantes de poliacrilamida al 6\%. Se utilizó el marcador de peso molecular HyperLadder IV (Bioline). La electroforesis se corrió en una cámara vertical Sequi-Gen GT Sequencing Cell (Bio Rad) durante 90 minutos a 1000V. Los fragmentos amplificados fueron visualizados mediante tinción con nitrato de plata a través del protocolo descrito por Benbouza et al. (2006).

\section{Diseño Experimental}

Para el tratamiento estadístico de los datos, se utilizó un diseño factorial evaluando cuatro Métodos de Extracción (niveles) y tres tipos de Tejido Foliar (factores); como control se empleó el protocolo del Kit comercial DNeasy 
Plant mini Kit de QIAGEN. Este diseño permitió evaluar la interacción entre factores y niveles. Para esto se realizó un Análisis de Componentes Principales (ACP) y un Análisis Factorial Múltiple (AFM), con el paquete estadístico software PAST (Palaeontological STatistics, ver. $1,75)$ con la plataforma de Windows.

\section{RESULTADOS Y DISCUSIÓN}

Al evaluar cada uno de los protocolos de extracción en ambas especies, se encontró que el método control, en este caso el Kit comercial de QIAGEN (Figura 1a), no fue útil en la extracción y amplificación del ADN en T. rosea, debido a que el Kit requiere tejidos jóvenes o que contengan niveles bajos de polifenoles ( $\mathrm{Li}$ et al. 2002), lo que fue limitante es esta especie dado que Martínez (2010) y Arbeláez et al. (2011), reportaron una presencia significativa de diversos metabolitos secundarios en esta especie, los cuales son muy estudiados en la actualidad a nivel farmacológico, ya que estos metabolitos son usados como compuestos activos para combatir muchas patologías. A lo anterior se le suma su elevado costo, lo que limitó la cantidad de muestras a evaluar (Li et al. 2002; Michiels et al. 2003; Deshmukh et al. 2007).

Aunque en muchos protocolos se plantea el hecho de que la extracción de ADN, se realiza preferiblemente a partir de tejidos jóvenes debido al menor contenido de polisacáridos, polifenoles y otros metabolitos secundarios (Zhang and McStewart 2000); esto es poco frecuente, ya que en la mayoría de los casos sólo se dispone de tejidos maduros, y por lo tanto es necesario determinar un procedimiento adecuado para la extracción selectiva del ADN
(Križman et al. 2006).

Con el método Doyle and Doyle (1990), se logró extraer ADN en ambas especies utilizando los tres tipos de tejido foliar (Figura $1 b)$, sin embargo fue T. rosea la que presentó mejores resultados. Esto dado que las células vegetales pueden lisarse con el detergente iónico, formando un complejo insoluble con los ácidos nucléicos en medio hiposalino. De ese modo, los polisacáridos, los compuestos fenólicos y los demás contaminantes permanecieron en el sobrenadante y pudieron eliminarse por lavado.

Teniendo en cuenta que el método de Porebski et al. (1997) es una modificación al propuesto inicialmente por Doyle and Doyle (1990), en ambos se encontraron resultados similares, ya que aunque se logró extraer ADN en ambas especies, fue $T$. rosea la que presentó una integridad mayor en el ADN (Figura 1c), dado que al incorporar una concentración considerable de $\mathrm{NaCl}$, combinado con PVP y carbón activado, se evitó la solubilización de los polifenoles y polisacáridos, por lo tanto estos contaminantes no precipitaron y pudieron eliminarse extrayendo la solución acuosa con cloroformo. De igual forma, al desnaturalizar las proteínas se facilitó la separación de la fase acuosa descartándola en el sobrenadante y precipitando los ácidos nucleicos en la fase orgánica.

En el caso del método de Dellaporta et al. (1983), fue útil en la extracción de ADN en ambas especies, sin embargo presentó mejores resultados C. alliodora (Figura 1d), ya que empleó el SDS, el cual es un compuesto tenso activo iónico, que ha sido utilizado por 

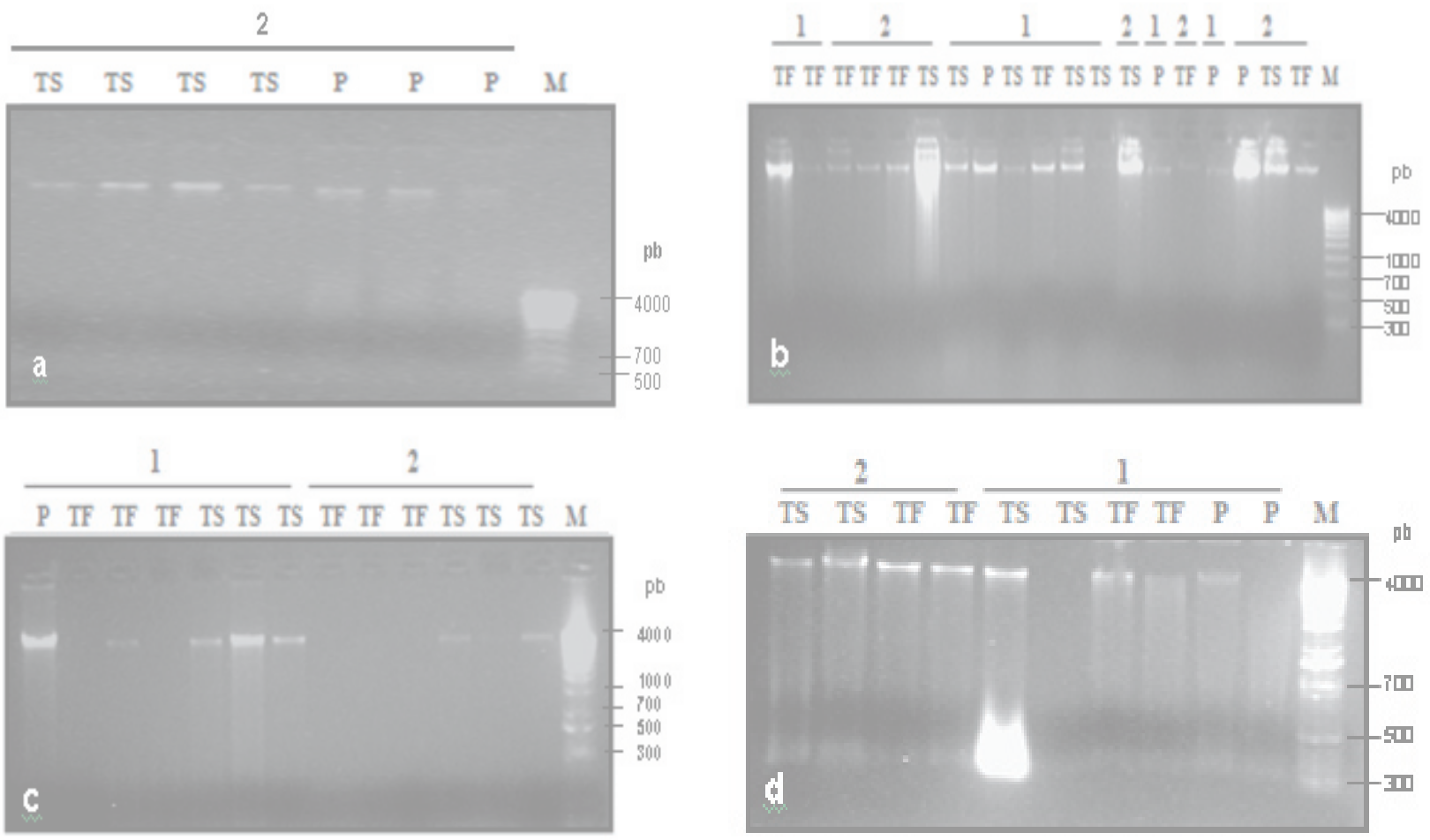

Figura 1. Obtención de ADN genómico con los diferentes protocolos de extracción. a) Kit de QIAGEN, b) Doyle \& Doyle (1990), c) Porebski et al. (1997) y d) Dellaporta et al. (1983), en las especies Tabebuia rosea (1) y Cordia alliodora (2). En: Tejido seco (TS), Tejido Fresco (TF), Plántulas (P), 1 kb DNA Ladder (M).

múltiples autores, debido a que disminuye notablemente los procesos de fenolización, garantizando una mayor preservación del ADN (Matasyoh et al. 2008).

Consecuentemente, al evaluar la cantidad de los ácidos nucleicos por espectrofotometría, se encontró que en los casos donde había presencia de proteínas en la muestra (A280), el cociente A260/A280 era considerablemente inferior a dichos valores, dificultando la determinación con exactitud de la cantidad de ácidos nucleicos. No obstante, en el estudio realizado por Michiels et al. (2003), se determinó que la cantidad y calidad del ADN aislado también dependían de la temperatura y la duración de la precipitación, ya que a temperaturas bajas la precipitación del ADN aumentó.
En el análisis espectrofotométrico, obtenido a partir de lecturas a 260nm y 280nm realizadas a las muestras de ADN extraídas en C. alliodora, se determinó que el método de Doyle and Doyle (1990) empleando plántulas, fue el que registró una mayor concentración

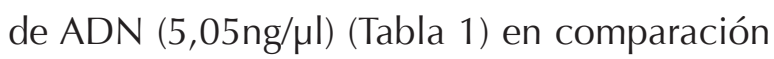
con el ADN obtenido empleando los tejidos y métodos restantes. También presentó un nivel de pureza significativo $(1,71)$, recordando que el cociente de los valores obtenidos a 260nm y a 280nm (A260/A280) proporciona una estimación del grado de pureza de los ácidos nucleicos, y deben oscilar aproximadamente de 1,7 a 2,0.

En contraste el método de Porebski et al. 1997, presentó una utilidad reducida, ya que solo se logró extraer ADN de tejido seco, con una 
Tabla 1. Cantidad y pureza del ADN con cuatro métodos de extracción y tres tipos de tejido foliar diferentes en la especie Cordia alliodora (Ruiz \& Pav.).

\begin{tabular}{|c|c|c|c|c|c|}
\hline Tipo Tejido & Métodos* & A 260 & A 280 & A $260 /$ A 280 & 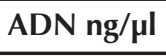 \\
\hline \multirow{4}{*}{ Fresco } & 1 & $0,21 \pm 0,07$ & $0,15 \pm 0,04$ & 1,40 & 1,05 \\
\hline & 2 & 0 & 0 & 0 & 0 \\
\hline & 3 & $0,74 \pm 0,10$ & $0,58 \pm 0,12$ & 1,28 & 3,70 \\
\hline & 4 & 0 & 0 & 0 & 0 \\
\hline \multirow{4}{*}{ Seco } & 1 & $0,20 \pm 0,06$ & $0,17 \pm 0,06$ & 1,18 & 1,00 \\
\hline & 2 & $0,17 \pm 0,03$ & $0,14 \pm 0,03$ & 1,21 & 0,85 \\
\hline & 3 & $0,54 \pm 0,11$ & $0,35 \pm 0,05$ & 1,54 & 2,70 \\
\hline & 4 & $0,07 \pm 0$ & $0,06 \pm 0$ & 1,17 & 0,35 \\
\hline \multirow{4}{*}{ Plántulas } & 1 & $0,07 \pm 0,01$ & $0,06 \pm 0$ & 1,17 & 0,35 \\
\hline & 2 & 0 & 0 & 0 & 0 \\
\hline & 3 & $1,01 \pm 0,47$ & $0,59 \pm 0,28$ & 1,71 & 5,05 \\
\hline & 4 & $0,38 \pm 0,10$ & $0,40 \pm 0,11$ & 0,95 & 1,90 \\
\hline
\end{tabular}

*Métodos de extracción empleados (1) Dellaporta et al. (1983), (2) Porebski et al. (1997), (3) Doyle \& Doyle (1990) y (4) Kit de QIAGEN.

$\mathrm{A}=$ Absorbancia en nanometros

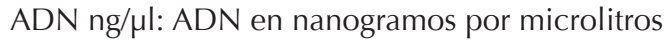

concentración de $0,85 \mathrm{ng} / \mu \mathrm{l}$ y un nivel de pureza de 1,21. Al igual que los resultados obtenidos con el Kit de QIAGEN debido a que solo se extrajo ADN a partir de tejido seco (0,35ng/ $\mu \mathrm{l})$ y plántulas $(1,90 \mathrm{ng} / \mu \mathrm{l})$, con un nivel de pureza de 1,17 y 0,95, respectivamente (Tabla
1). En el caso de T. rosea, el ADN obtenido por el método de Porebski et al. 1997, utilizando tejido fresco $(0,65 \mathrm{ng} / \mu \mathrm{l})$ y plántulas $(0,40 \mathrm{ng} /$ $\mu \mathrm{l})$, presentó una concentración reducida, al igual que el nivel de pureza $(1,18$ y 1,14$)$ respectivamente (Tabla 2). Contrastando con el

Tabla 2. Cantidad y pureza del ADN con cuatro métodos de extracción y tres tipos de tejido foliar diferentes en la especie Tabebuia rosea (Bertol).

\begin{tabular}{lcrrrr}
\hline \multicolumn{1}{c}{ Tipo Tejido } & Métodos* & A 260 & A 280 & A 260/A 280 & ADN $\mathbf{~ g / ~} \mathbf{\mu l}$ \\
\hline \multirow{3}{*}{ Fresco } & 1 & $0,35 \pm 0,14$ & $0,24 \pm 0,09$ & 1,49 & 1,76 \\
& 2 & $0,13 \pm 0,06$ & $0,11 \pm 0,05$ & 1,18 & 0,65 \\
& 3 & $0,38 \pm 0,13$ & $0,26 \pm 0,08$ & 1,46 & 1,90 \\
& 4 & 0 & 0 & 0 & 0 \\
Seco & 1 & $0,31 \pm 0,25$ & $0,21 \pm 0,15$ & 1,47 & 1,53 \\
& 2 & $0,64 \pm 0,02$ & $0,47 \pm 0,04$ & 1,36 & 3,20 \\
& 3 & $1,35 \pm 0,07$ & $0,91 \pm 0,05$ & 1,48 & 6,75 \\
Plántulas & 4 & 0 & 0 & 0 & 0 \\
& 1 & $0,34 \pm 0,08$ & $0,22 \pm 0,05$ & 1,55 & 1,70 \\
& 2 & $0,08 \pm 0,04$ & $0,07 \pm 0,03$ & 1,14 & 0,40 \\
& 3 & $0,47 \pm 0,03$ & $0,27 \pm 0,02$ & 1,74 & 2,35 \\
\hline
\end{tabular}

*Métodos de extracción empleados (1) Dellaporta et al. (1983), (2) Porebski et al. (1997), (3) Doyle \& Doyle (1990) y (4) Kit de QIAGEN.

$\mathrm{A}=$ Absorbancia en nanometros

ADN ng/ $\mu \mathrm{l}:$ ADN en nanogramos por microlitros 
método de Doyle and Doyle (1990), empleando plántulas, el cual presentó un nivel de pureza significativo $(1,74)$, sin embargo sólo se obtuvo $2,35 \mathrm{ng} / \mu \mathrm{l}$ de ADN. Cabe resaltar que en T. rosea no se pudo extraer ADN genómico a partir de tejido seco, fresco y plántulas, empleando el Kit comercial de QIAGEN, por ende no se obtuvieron datos espectrofotométricos.

Para evaluar la calidad se empleó productos de microsatélites después de la amplificación del ADN genómico, donde se determinó que aun en los casos en que se logró extraer ADN empleando un método o un tejido especifico, este no garantizaba que fuese amplificable, Concordando con lo manifestado por Grattapaglia (1994), donde ilustra el hecho de que la presencia de metabolitos secundarios, presenta inicialmente dificultades en la reacción en cadena de la polimerasa (PCR) inhibiendo la acción de la Taq polimerasa. En C. alliodora amplificó el ADN obtenido con los métodos de Doyle \& Doyle (1990) y
Dellaporta et al. (1983), en los tres tipos de tejido foliar. Y con el Kit de QIAGEN sólo amplificó el ADN obtenido de tejido seco y plántulas (Figura 2a). Para la especie T. rosea el ADN obtenido a partir de tejido fresco y plántulas con los métodos Doyle and Doyle (1990), Dellaporta et al. (1983), y Porebski et al. (1997), fueron útiles para la amplificación empleando microsatélites, descartando el tejido seco, dado el rendimiento ineficiente en la amplificación (Figura 2b).

Como resultado del Análisis de Componentes Principales (ACP) en ambas especies, se logró transformar un conjunto de variables en un número menor de dimensiones o componentes, las cuales contenían la mayor parte de la información (varianza) del conjunto inicial. En C. alliodora el Componente 1, explicó el 84,48\% de la varianza, presentando la mayor correlación positiva con las variables absorbancia (ABS260) y concentración en ng/ $\mu \mathrm{l}$, es decir, que en este caso el conjunto de datos
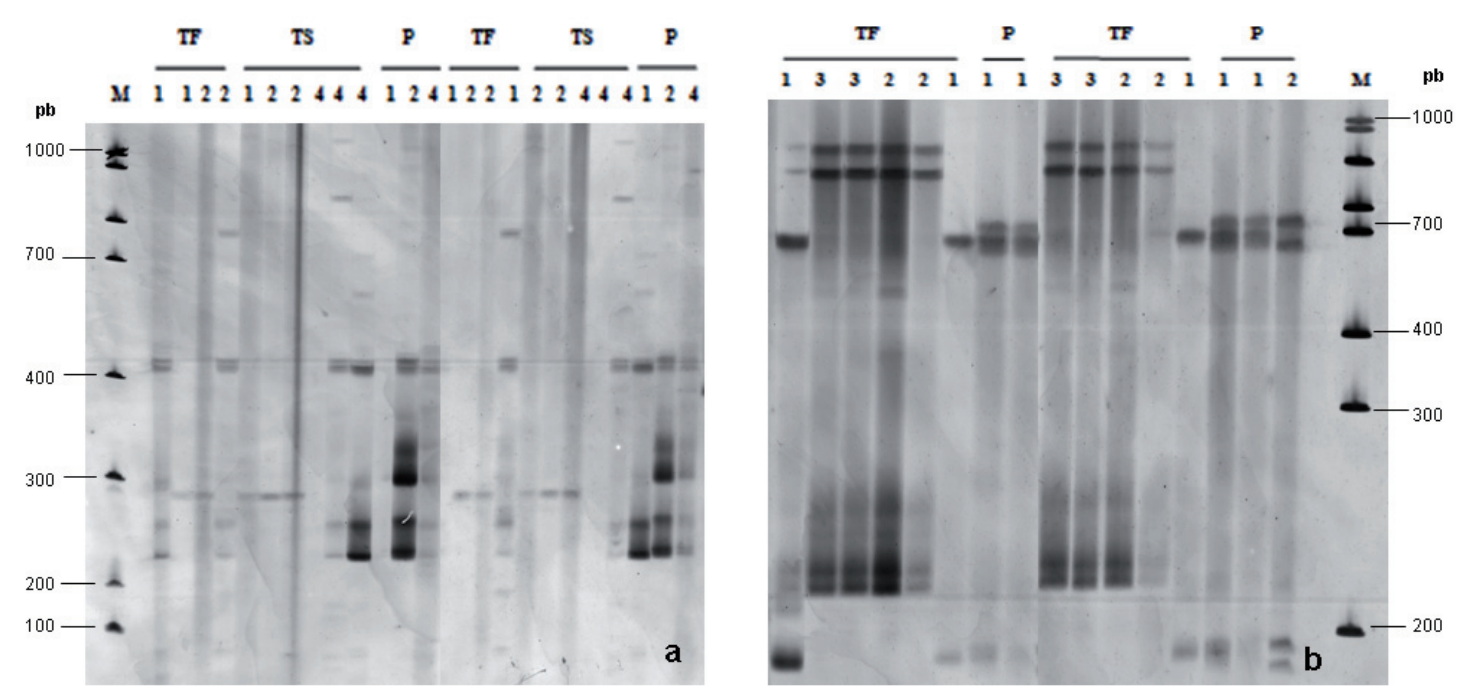

Figura 2. Productos de SSR después de la amplificación del ADN genómico obtenido a partir de tres tipos de tejido foliar y cuatro métodos de extracción en la especies a) Cordia alliodora y b) Tabebuia rosea. Métodos de extracción: (1) Dellaporta et al. (1983) (2) Doyle \& Doyle (1990) (3) Porebski et al. (1997), y (4) Kit de QIAGEN. Tipo de tejido: T. seco (TS), T. Fresco (TF), Plántulas (P), Hyper Ladder IV (M). 
se redujo a sólo dos variables (dos componentes importantes), que influían directamente en la elección del método y tejido apropiado para la extracción de ADN genómico. El Componente 2, en esta especie no se consideró ya que sólo explicaba el $15,3 \%$ restante con la variable absorbancia (A260/A280) (Tabla 3). En cuanto a la especie $T$. rosea el Componente 1, explicó el $78,81 \%$ de la varianza, contenida en las variables absorbancia (A260) y concentración en $\mathrm{ng} / \mu \mathrm{l}$, reduciendo de igual forma el número de variables a dos dimensiones principales. En este caso el Componente 2, explicó el 21,15\% con la variable A260/A280 la cual presentó una correlación positiva muy alta (casi 1), con lo cual se interpretó como un variable independiente (Tabla 3).

Posterior al Análisis de Componentes Principales (ACP), se realizó un Análisis Factorial Múltiple (AFM), el cual es un método adaptado al manejo de datos en las que un mismo conjunto de tratamientos se describe a través de varios grupos de variables. Teniendo en cuenta que se trabajó conjuntamente con variables cuantitativas y cualitativas, en distintos periodos de tiempo, es por esto que se incluyó también los resultados de la PCR. Cuando se evaluó la amplificación en el ADN obtenido se observaron diferencias en los métodos y tejidos empleados. Por lo tanto, al considerar todos los factores, se encontró que el método más apropiado para la extracción de ADN en C. alliodora fue el propuesto por Dellaporta et al. (1983), empleando cualquiera de los tres tipos de tejido foliar, ya que fue amplificable (Figura 3a). En el caso de T. rosea el AFM, demostró que los métodos adecuados de extracción fueron: Doyle and Doyle (1990), Dellaporta et al. (1983), y Porebski et al. (1997), empleando tejido fresco o plántulas. En esta especie el ADN obtenido a partir de tejido seco no fue eficiente, ya que no amplificó (Figura 3b).

También, seconsideró el método de recolección y almacenamiento del material vegetal; en ambas especies se obtuvo ADN a partir de plántulas, y hojas recolectadas de arboles maduros, pero estas se debían transportar en hielo para prolongar la aparición de procesos de fenolización. En el caso del tejido seco, las hojas se recolectaron en bolsas herméticas con gel de sílice granulado, y se dejó alrededor de una semana en el laboratorio. Para el almacenamiento del tejido recolectado, se determinó que en ambas especies después de macerar con nitrógeno liquido, el tejido fresco

Tabla 3. Contribución de las variables a los primeras componentes principales en las especies Cordia alliodora (Ruiz \& Pav.) y Tabebuia rosea (Bertol).

\begin{tabular}{|c|c|c|c|}
\hline \multirow{2}{*}{ Variables } & Componente 1 & Componente 1 & Componente 2 \\
\hline & Cordia alliodora & \multicolumn{2}{|c|}{ Tabebuia rosea } \\
\hline A260 & 0,5416 & 0,5595 & $-0,1231$ \\
\hline A280 & 0,5075 & 0,5526 & $-0,2073$ \\
\hline A260/280 & 0,3946 & 0,2618 & 0,9627 \\
\hline $\mathrm{ng} / \mu \mathrm{l}$ & 0,5416 & 0,5595 & $-0,1226$ \\
\hline Exp. Var & 3,37949 & 3,15 & 0,845836 \\
\hline Prp. Tot & 84,487 & 78,81 & 21,15 \\
\hline
\end{tabular}

A: Absorbancia en nanometros, ng/ $\mu$ l: nanogramos por microlitro; Exp. Var: Varianza esperada; Prp. Tot: Probabilidad total. 

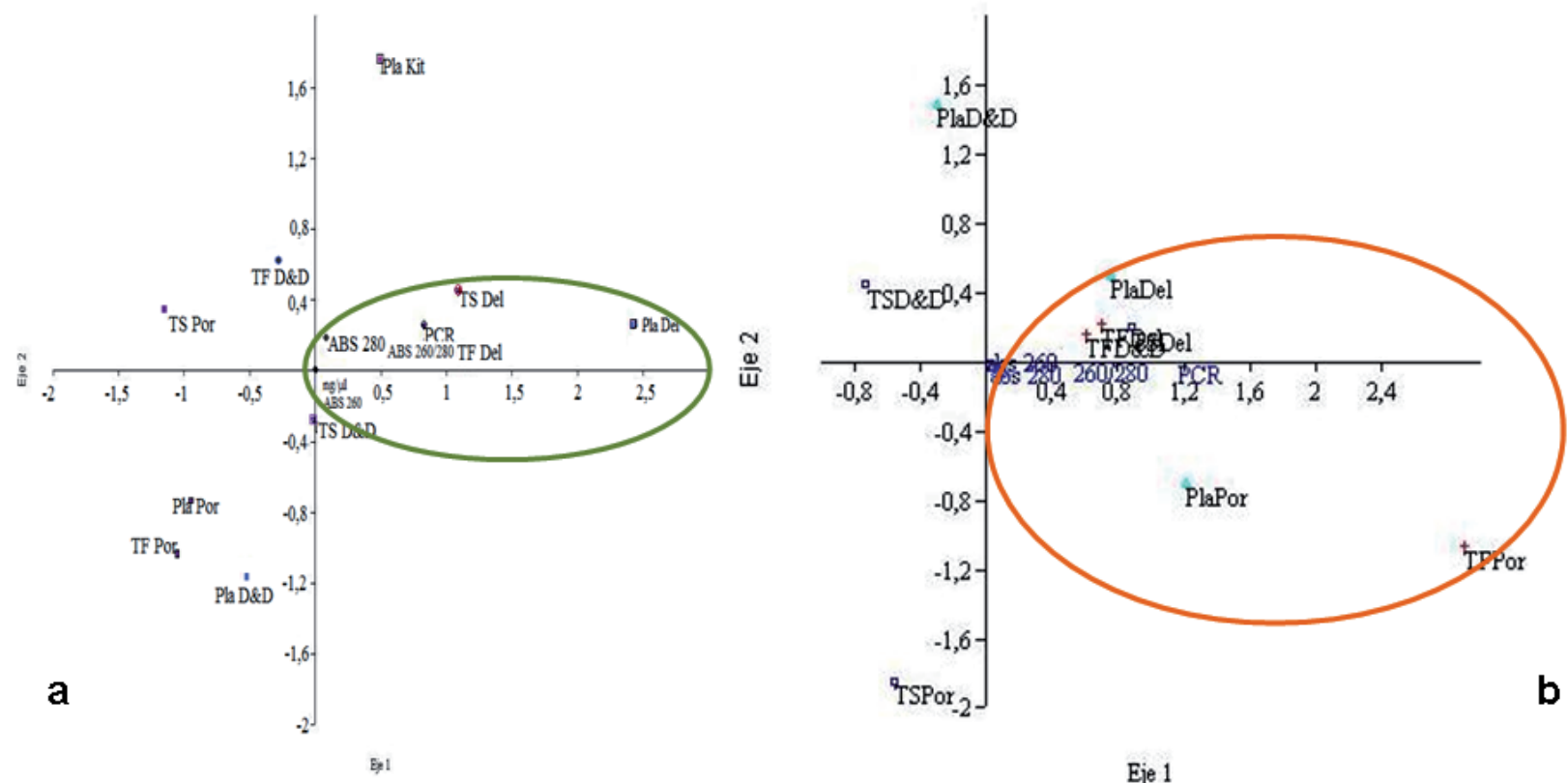

Eje 1

Figura 3. Análisis Factorial Múltiple teniendo en cuenta las absorbancias, concentración, método y tipo de tejido, considerando además los resultados de la PCR, en las especies a) Cordia alliodora y b) Tabebuia rosea.

se puede almacenar a $-70^{\circ} \mathrm{C}$ en tubos cónicos de $15 \mathrm{ml}$, sin limitar posteriormente la cantidad y amplificación del ADN, concordando con otras investigaciones donde se ha observado que para preservar las muestras por tiempos prolongados es necesario almacenarlas en congeladores de $-70^{\circ} \mathrm{C}$ y $-80^{\circ} \mathrm{C}$ o dispositivos de nitrógeno líquido (Marulanda et al. 2006).

No obstante, en C. alliodora se obtuvieron resultados exitosos, en el almacenamiento del tejido seco, lo cual fue muy importante ya que en muchas ocasiones es necesario almacenar el tejido en condiciones seco o semi-seco, y esto exige el estudio no solo de un protocolo de extracción y el uso de diferentes tejidos, sino también la evaluación de métodos de almacenamiento (Matasyoh et al. 2008).

En síntesis, se pudo determinar que el protocolo óptimo para la extracción de ADN teniendo en cuenta la cantidad y amplificación en $C$. alliodora, fue el propuesto por Dellaporta et al. (1983), empleando cualquiera de los tres tipos de tejido foliar. A diferencia de los resultados obtenidos en T. rosea, donde el método no presentó diferencias significativas, lo que puso de manifiesto el hecho de que el tipo de tejido en esta especie afectó significativamente los resultados de extracción y amplificación, ya que se observó mejores resultados en plántulas y tejido fresco.

\section{CONCLUSIONES}

Esta investigación demostró que el procedimiento de extracción de ADN y el tipo de muestra afectaron significativamente el rendimiento y la calidad, así como la amplificación por microsatélites en las especies T. rosea y $C$. alliodora. Se recomienda no emplear Kits comerciales en especies forestales, ya que en muchas ocasiones, no se producen rendimientos eficientes de ADN amplificable, 
debido al requerimiento de tejidos jóvenes con niveles bajos de metabolitos secundarios. Finalmente, se pudo inferir que una adecuada selección de metodología y tipo de muestra, son necesarias para obtener resultados fiables basados en marcadores, ya que evidentemente la cantidad y la calidad del ADN variaron dependiendo de la especie y el tipo de tejido empleado.

\section{AGRADECIMIENTOS}

Los autores agradecen al Ministerio de Agricultura y Desarrollo Rural de la República de Colombia y a la Universidad Tecnológica de Pereira por la financiación de la investigación. Y un especial agradecimiento al Dr. Orlando Coto por el asesoramiento en los análisis estadísticos y a la Administradora Juliana Arias por el apoyo logístico al presente trabajo.

\section{REFERENCIAS}

Alaey, M., Naderi, R., Vezvaei, A., Khalighi, A. and Salami, A. 2005. Comparing study between four different methods of genomic DNA extraction from Cyclamen persicum Mill. International Journal of Agriculture \& Biology 7(6): 882-884.

Arbeláez, J., Acevedo, J. y Jaramillo, R. 2011. Metabolitos secundarios en el guayacán amarillo y en el guayacán rosado. Scientia et Technica 47:297- 301.

Becker, J.M., Caldwell, G.A. and Zachgo, E.A. 1996. Biotechnology: A Laboratory Course. Second Edition. Academic press. p216.
Benbouza, H., Jacquemin, J.M., Baudoin, J.P. and Mergeai, G. 2006. Optimization of a reliable, fast, cheap and sensitive silver staining method to detect SSR markers in polyacrylamide gels. Biotechnol. Agron. Soc. Environ. 10(2):77-81.

Borge, W.A. 2008. Producción e incrementos de madera y carbono de laurel (Cordia alliodora) y cedro amargo (Cedrela odorata L.) de regeneración natural en cacaotales y bananales indígenas de Talamanca, Costa Rica. Tesis Mag. Sc. Turrialba, Costa Rica, IICA.

Boshier, D.H. and Mesén, F. 1989. Breeding population of Cordia alliodora in Costa Rica. In Conference on Breeding Tropical Trees: Population Structure and Genetic Improvement Strategies in Clonal and Seedling Forestry (1988, Pattaya, Tailandia). Procceedings IUFRO Conference. Arlington, USA. Winrock International, p406-407.

CONIF. 2002. Aplicación de los métodos de estacas e injertos para la propagación vegetativa de Cordia alliodora (Ruiz \& Pavon) Oken y Tabebuia rosea (Bertol) DC. Serie de documentación No 47 Bogotá Colombia. p61.

Dellaporta, S.L., Wood, J. and Hicks, J.B. 1983. A plant DNA Minipreparation: Version II. Plant Mol. Biol. Rep. 1(4):19-21.

Deshmukh, V.P., Thakare, P.V., Chaudhari, U.S. and Gawande, P.A. 2007. A simple method for isolation of genomic DNA from fresh and dry leaves of Terminalia 
arjuna (Roxb.) Wight and Argot. Electronic Journal of Biotechnology 10(3):468-472.

Doyle, J.J. and Doyle, J.L. 1990. Isolation of plant DNA from fresh tissue. Focus 12(1):13-15.

Grattapaglia, D. 1994. Genetic mapping of quantitatively inherent economically important traits in Eucalyptus Ph.D. Dissertation, North Carolina State University, p289.

Keb-Llanes, M., González, G., Chi-Manzanero, B. and Infante, D. 2002. A Rapid and Simple Method for Small-Scale DNA Extraction in Agavaceae and Other Tropical Plants. Plant Molecular Biology Reporter 20(3):299.

Kitajima, K. 2002. Do shade-tolerant tropical tree seedlings depend longer on seed reserves? Functional growth analysis of three Bignoniaceae species. Functional Ecology 16(4):433-444.

Križman, M., Jakše, J., Baričevič, D., Javornik, B. and Prošek, M. 2006. Robust CTABactivated charcoal protocol for plant DNA extraction. Acta Agriculturae Slovenica 87(2):427-433.

Li, Y. X., Su, Z. X. and Chen, F. 2002. Rapid Extraction of Genomic DNA From Leaves and Bracts of Dove Tree (Davidia involucrata). Plant Molecular Biology Reporter 20(2):185.
López, A. 2009. Caracterización con microsatélites de Tabebuia rosea (Bertol.) DC. en ensayos de procedencias y progenies en Colombia. Tesis de maestría en Biología Vegetal, Universidad de Caldas, Manizales - Colombia.

Martínez, A.J. 2010. Principios activos en el Guayacán Amarillo (Tabebuia chrysantha Jacq. Nicholson, Bignoniaceae) y en el Guayacán Rosado (Tabebuia rosea Bertol. DC. Proyecto de Grado, Universidad del Quindío, Armenia - Colombia.

Marulanda, M., Claroz, J. y López, A. 2006. Caracterización molecular de progenies de aliso Alnus acuminat H.B.K spp acuminata, mediante marcadores AFLP. Scientia et Technica 32:463-468.

Matasyoh, L.G., Wachira, F.N., Kinyua, M.G., Thairu, A.W. and Mukiama T.K. 2008. Leaf storage conditions and genomic DNA isolation efficiency in Ocimum gratissimum L. from Kenya. African Journal of Biotechnology 7(5):557-564.

Mesén, F. 1994. Ensayos de procedencias en especies forestales: establecimiento, manejo, evaluación y análisis. In: Manual sobre mejoramiento genético forestal con referencia especial a América Central. Centro Agronómico Tropical de Investigación y Enseñanza CATIE, Turrialba, Costa Rica. p25-44.

Michiels, A., Ende, W.V. den, Tucker, M., Riet L.V. and Laere A.V. 2003. Extraction of high-quality genomic DNA from 
latex-containing plants. Analytical Biochemistry 315(1):85-89.

Narayanan, C., Dubey, S., Wali, S.A., Shukla, N., Kumar, R., Mandal, A.K. and Ansari, S.A. 2006. Optimization of DNA extraction for ISSR studies in Tectona grandis L.f. - an important forest tree species. African Journal of Biotechnology 5(13):1220-1223.

OFI (Oxford Forestry Institute) - CATIE (Centro Agronómico Tropical de Investigación y Enseñanza). 2003. Árboles de Centroamérica: un manual para extensionistas, p1079.

Porebski, S., Bailey, L.G. and Baum, B.R. 1997. Modification of CTAB DNA extraction protocol for plants containing high polysaccharide and polyphenol components. Plant Molecular Biology Reporter 15(1):8-15.

Rout, G.R., SamaL, S., Nayak, S., Rashmi, M.N., Lenka, P.C. and Das, P. 2002. An Alternative Method of Plant DNA Extraction of Cashew (Anacardium occidentale L.) for Randomly Amplified Polymorphic DNA (RAPD) analysis. Gartenbauwissenschaft 67(3):114-118.
Sghaier, Z.A. and Mohammed, C. 2005. Genomic DNA extraction method from pearl millet (Pennisetum glaucum) leaves. African Journal of Biotechnology 4(8):862-866.

Sharma, A.D., Gill, P.K. and Singhdna, P. 2002. Isolation From Dry and Fresh Samples of Polysaccharide-Rich Plants. Plant Molecular Biology Reporter 20(4):415.

Vit, P. 2004. Tabebuia rosea (Bertol.) DC. Ficha botánica de interés apícola en Venezuela, No. 7 Apamate. Revista Facultad de Farmacia 46(1):57-59.

Zamudio, F. y Guerra, F. 2002. Especies forestales de rápido crecimiento con énfasis en el género Populus. Universidad de Talca. Facultad de Ciencias Forestal. Chile, p1-68.

Zhang, J. and Mcstewart, J.D. 2000. Economical and rapid method for extracting cotton genomic DNA. Journal of Cotton Science 4(3):193-201 